\title{
Effect of Deposition Time on the Optoelectrical Properties of Electrospun PAN/AgNO 3 Nanofibers
}

\author{
Sebnem Duzyer Gebizli \\ Bursa Uludag University, Faculty of Engineering, Textile Engineering Department, Gorukle Campus 16059 Nilüfer, Bursa, Turkey
}

Corresponding Author: Sebnem Duzyer Gebizli, sebnemduzyer@uludag.edu.tr

\begin{abstract}
The aim of this study is to produce optically transparent nanofibers with adequate electrical conductivity for optoelectrical applications where transparency and conductivity are needed. Therefore, conductive polyacrylonitrile/silver nitrate $\left(\mathrm{PAN} / \mathrm{AgNO}_{3}\right)$ nanofibers were produced by electrospinning with different deposition times ranging from 1 minute to 10 minutes. The effect of deposition time on the sheet resistance and optical transparency of the nanofibers were investigated. The surface characteristics, electrical properties and transmittance values of the electrospun mats were evaluated. Nanofibers with diameters under $700 \mathrm{~nm}$ were obtained. With the increasing deposition time, the sheet resistance and transparency of the samples were decreased. In order to figure out the optimum deposition time, the figures of merit of the samples were calculated. The figures of merit of the samples showed that the sample deposited for three minutes gave the best performance among the others. It was seen that conductive $\mathrm{PAN} / \mathrm{AgNO}_{3}$ nanofibers are promising for optoelectrical applications.
\end{abstract}

\author{
ARTICLE HISTORY \\ Received: 21.05.2019 \\ Accepted: 11.02.2020
}

\section{KEYWORDS}

Sheet resistance, optical transparency, polyacriylonitrile, silver nitrate, electrospinning, nanofiber

\section{INTRODUCTION}

Transparent conductive electrodes (TCEs), which conduct electrical current and transmit light, play important roles in many optoelectrical applications such as thin-film solar cells, liquid-crystal displays, light-emitting diodes, sensors, energy harvesting devices, field-effect transistors and photovoltaic devices. Two crucial parameters are expected from a good TCE: low sheet resistance and high optical transparency $[1,2]$.

Sheet resistance (Rs) (also known as surface resistivity) is the measurement of resistance across the surface of a material in contact with the electrodes. It can be defined as the electric current flowing across a surface as the ratio of DC voltage drop per unit length to the surface current per unit width and is expressed in ohms per square $(\Omega / s q)[3,4]$.
Optical transparency (T) is another important parameter to define a TCE. It can be defined as allowing light to pass through the material without being scattered. A good TCE should have high optical transparency with low sheet resistance $[5,6]$.

In order to meet these requirements, researchers have been investigated many conductive materials including indium tin oxide (ITO), metal oxides, carbon based materials like carbon nanotubes, graphene and graphite, metal nanowires etc. These materials are highly conductive as they have low resistance values depending on their production method, size and structure [7-10]. However, these materials also have disadvantages such as high cost/challenging production methods, rarity of the raw materials, or brittleness [5, 6]. This drives the search for an alternative material as TCEs.

To cite this article: Düzyer Gebizli S. 2020. Effect of Deposition Time on the Optoelectrical Properties of Electrospun $\mathrm{PAN}_{\mathrm{AgNO}} \mathrm{Ag}_{3}$ Nanofibers. Tekstil ve Konfeksiyon, 30 (1), 29-34. 
Nanofibers have gained attention due to their distinguishing properties such as high surface area per volume, low weight and high mechanical properties [11-14]. The electrical conductivity values of the nanofibers are increased due to the confinement [15]. Therefore, the interest for the usage of nanofibers in electrical applications are growing. Since thin film production for optoelectronic applications are difficult and costly, conductive nanofibers are an alternative for such applications. Electrospinning is the most used and well-known method for nanofiber production. The method involves fabrication of nano-scaled fibers from polymer solutions using electrical forces [11-14].

There are different methods to make conductive nanofibers by electrospinning including using intrinsically conductive polymers or adding a conductive compound into the nonconductive polymers [16].

Electrospinning of intrinsically conductive polymers (namely, polyaniline (PANI), polypyrrole (PPy), polythiophene, poly (3,4-ethylenedioxythiophene) (PEDOT)) for the production of TCEs have been thoroughly studied in several applications such as biosensors, biomedical applications, energy storage, etc [16-21]. Although these polymeric nanofibers show lower conductivities compared to ITO, carbon nanotubes, or graphene; there are also many studies on the improvement of their electrical properties. However, the processability of these polymers is challenging. They cannot be melt processed and are insoluble in most solvents [16-21].

Another approach to produce TCEs is to fabricate conductive electrospun nanofibers by adding a conductive component into a non-conductive polymer. In this method, the polymer called as "template polymer" carries the conductive component. Conductive component can be a metal (such as silver, copper, gold, etc.), carbon black nanoparticles, an ionic liquid, carbon fibers or nanotubes, conductive polymers or their combinations [16, 22-24].

Nanofibers with silver particles have application areas from antibacterial materials to conductive composites as they show high optical, antimicrobial, electronic and magnetic properties. They can be also used as fillers for composites to be used in electromagnetic shielding [25-27]. One of the challenges in adding silver particles into the nanofibers is to prevent the agglomeration of silver particles in the electrospinning solution. Generally, silver nitrate $\left(\mathrm{AgNO}_{3}\right)$ is added into the electrospinning solution and nanofibers are produced from $\mathrm{AgNO}_{3} /$ polymer solutions. The process is followed by a reduction treatment to form silver nanoparticles within the nanofibers. In literature, it was reported that the reduction treatment can be carried out by heating and/or chemical reduction or photo-reduction using UV irritation and chemical reduction is more effective compared to other methods [24, 28, 29]. The researchers also reported that the electrical properties of these structures may vary from hundreds of ohms to megaohms depending on nanofiber properties (thickness, diameter, fiber uniformity, distribution of the conductive component, etc.), solution properties (concentration of the components, homogenous solution preparation, etc.), electrospinning parameters (flow rate, applied voltage, distance between the needle and the collector, etc.) and reduction process (type and duration of the reduction, etc.) [24, 28]. Although, the properties of these structures are lower compared to highly conductive materials (ITO, metals, graphene, etc.), these values can be adequate for some special applications.

In this study the effect of deposition time on the sheet resistance and optical transparency of polyacrylonitrile/ silver nitrate $\left(\mathrm{PAN} / \mathrm{AgNO}_{3}\right)$ nanofibers were investigated. For this purpose, $\mathrm{PAN} / \mathrm{AgNO}_{3}$ nanofibers were produced by electrospinning. PAN was chosen as template polymer due to its low cost and availability and $\mathrm{AgNO}_{3}$ was chosen as conductive component due to its excellent electrical properties. Electrospun nanofibers were collected on glass substrates with different deposition times ranging from 1 minute to 10 minutes. The surface characteristics, sheet resistance and transmittance values of the electrospun mats were evaluated. The originality of this study is to establish a relationship between electrical and optical properties. Therefore, the figures of merit calculations, which define the performance of transparent conductive electrodes, were also added to the study in order to figure out this relationship and the sample with the optimum optoelectrical properties.

\section{MATERIALS AND METHODS}

\subsection{Materials}

In this study, commercially available polyacrylonitrile (PAN) (Mw: 200-240 kDa), N,N-dimethylformamide (DMF) (Sigma-Aldrich), silver nitrate $\left(\mathrm{AgNO}_{3}\right)$ (Tekkim Laboratory Chemicals) and sodium borohydride $\left(\mathrm{NaBH}_{4}\right)$ (Sigma-Aldrich) were used for the production of conductive nanofibers. All the chemicals were used without further purification.

\subsection{Methods}

A schematic view of the procedure followed in this study is given in Figure 1.

Solution preparation: A blend of $\mathrm{PAN} / \mathrm{AgNO}_{3}$ solution was prepared in DMF. In order to prepare $\mathrm{PAN} / \mathrm{AgNO}_{3}$ nanofibers, $7 \%$ wt. PAN was dissolved in DMF and stirred on a hot plate at $75{ }^{\circ} \mathrm{C}$ until it was dissolved completely. Afterwards, $\mathrm{AgNO}_{3}$ was added into the PAN solution with a weight of $3 \%$ of the polymer and sonicated for 2 minutes using a Velp Scientifica OV5 homogenizer (OV5 Homogenizer, Velp Scientifica). 


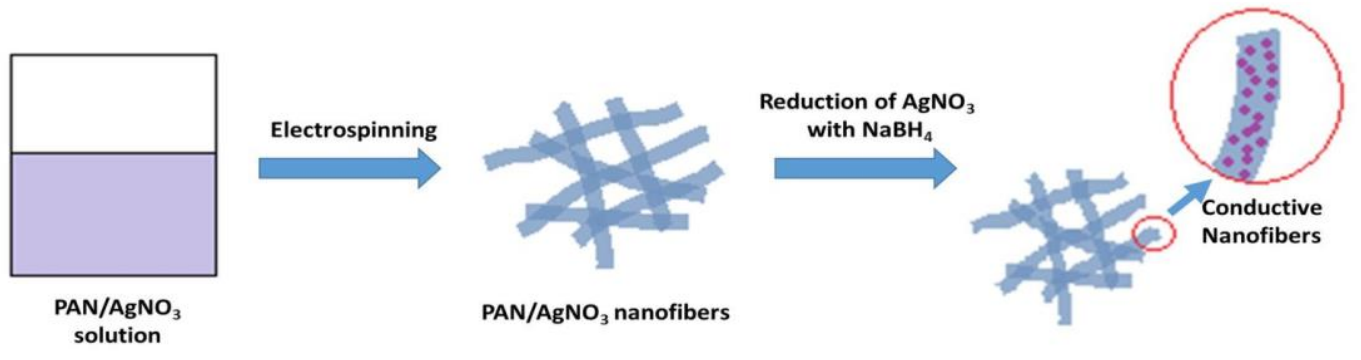

Figure 1. Schematic view of the procedure

Electrospinning of $\mathrm{PAN} / \mathrm{AgNO}_{3}$ solutions: In this study, electrospinning (Nanospinner NE300, Inovenso) was used to produce $\mathrm{PAN} / \mathrm{AgNO}_{3}$ nanofibers by using a single nozzle with an internal diameter of $0.8 \mathrm{~mm}$ at a flow rate of $1 \mathrm{ml} / \mathrm{h}$. The applied voltage was $18 \mathrm{kV}$ and the distance was kept at $13.5 \mathrm{~cm}$. The nanofibers were collected on a glass slide placed on a rotating disc with a speed of $100 \mathrm{rpm}$. The schematic view of the electrospinning setup used in this study is given in Figure 2.

The duration of the deposition time directly affects the optical transparency and the thickness of the samples, which also affects the sheet resistance. Preliminary studies showed that under 1 minute of deposition time, the thickness and the sheet resistance values of the samples were too low to measure. Above 10 minute of deposition time the optical transparency values of the samples were too low for optoelectronic applications. Therefore, the duration of the electrospinning was kept between 1-10 minutes.

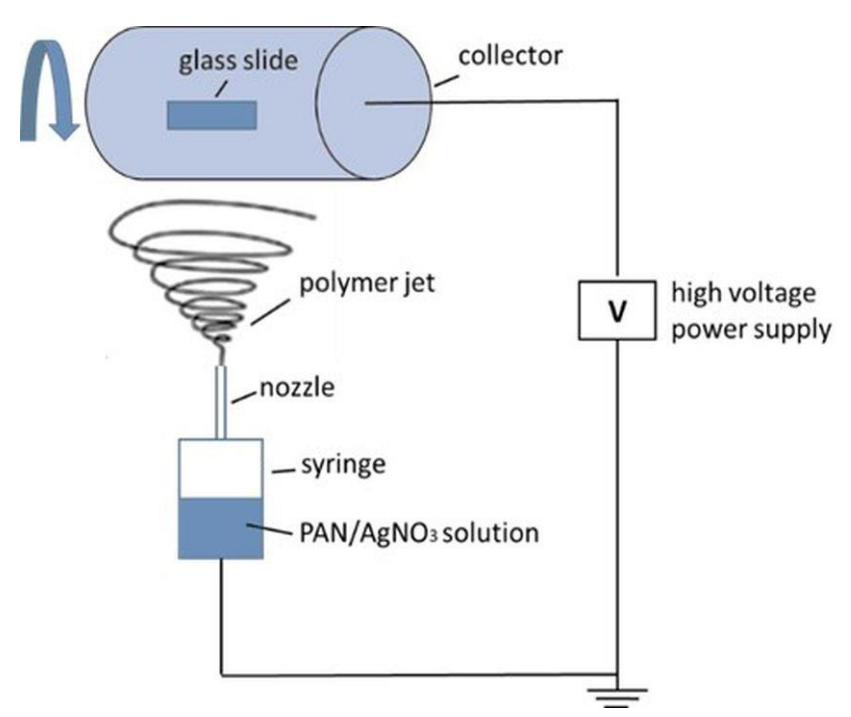

Figure 2. Schematic view of the electrospinning setup

Reduction process: In order to make $\mathrm{PAN} / \mathrm{AgNO}_{3}$ nanofibers conductive, a reduction process should be carried out. In the reduction process, $\mathrm{AgNO}_{3}$ is reduced to $\mathrm{Ag}[16,28-30]$. In this study, a chemical reduction was performed after electrospinning by using $\mathrm{NaBH}_{4}(1 \%$ wt. in water) to form silver nanoparticles within the fiber (Equation (1)). Thus, conductive nanofibers were obtained. Preliminary studies showed that reduction duration has a significant effect on the conductivities of nanofibers and the highest conductivity was achieved with longer durations [30]. Therefore, the same procedure was followed in this study. After reduction, the samples were dried at $40{ }^{\circ} \mathrm{C}$ for 2 hours in an incubator (Nüve-EN 025) and kept in room conditions for 2 days.

$\mathrm{AgNO}_{3}+\mathrm{NaBH}_{4} \rightarrow \mathrm{Ag}+\mathrm{H}_{2}+\mathrm{B}_{2} \mathrm{H}_{6}+\mathrm{NaNO}_{3}$

Characterization of PAN/AgNO ${ }_{3}$ nanofibers: A digital micrometer was used to calculate the thickness of the mats. The diameters and the morphologies of the nanofibers were examined by a Carl Zeiss Evo 40 scanning electron microscope (SEM). The sheet resistance values of the nanofibers were measured by a Four-Point Probe System (FPP 470-Entek Elektronik). Optical transparency values of the nanofibers were obtained by using a UV-visible spectrophotometer (Shimadzu- UV 3600 plus) with $0.1 \mathrm{~nm}$ resolution in the $280-2500 \mathrm{~nm}$ range. Specifically, the visible spectrum $(380-750 \mathrm{~nm}$ spectrum band) was considered for each sample [31-33].

In this study, five sets of samples were produced from 1 min to $10 \mathrm{~min}$. The thickness, the sheet resistance and the transparency measurements were performed on these samples. Average values for each sample were recorded.

Calculation of Figure of Merit: The figure of merit $\left(\Phi_{\mathrm{TC}}\right)$ is a useful tool to compare the performance of transparence conductive coatings when their electrical sheet resistance and optical transmission are known. It is derived from optical transparency and sheet resistance values and it can be used to predict transparent electrode properties of a candidate material. Higher figure of merit results in a better quality of transparent conductive electrode [33-37]. The figure of merit is first introduced by Fraser and Cook to understand the performance of conductive and transparent films of $\mathrm{In}_{2-\mathrm{x}} \mathrm{Sn}_{\mathrm{x}} \mathrm{O}_{3-\mathrm{y}}$ [34]. They obtained the figure of merit simply by dividing optical transparency by sheet resistance of the film given in Equation (2),

$\Phi_{\tau C}=\frac{\tau}{R_{S}}$ 
where $\mathrm{T}$ is the optical transmittance at $500 \mathrm{~nm}$ and Rs is the sheet resistance. The equation is modified by Haacke as described in Equation (3) [35],

$$
\Phi_{\tau C}=\frac{\tau^{x}}{R_{S}}
$$

where $\mathrm{T}$ is the optical transmittance at $550 \mathrm{~nm}$ and Rs is the sheet resistance. Values of $\mathrm{x}$ equal to 10, 20, and 100 lead to transmissions of $90 \%, 95 \%$, and $99 \%$, respectively. Since few applications require more than $90 \%$ transmission, Haacke settled on $\mathrm{x}=10$ [36].

There are also other figures of merit calculations reported in the literature [36]. However, the figures of merit given in Equation (2) and (3) are useful functions for comparison purposes [33-37]. Therefore, in this study the figure of merit was obtained by using Equation (3).

\section{RESULTS AND DISCUSSIONS}

Results of mat thickness, sheet resistance, and transparency measurements and the figures of merit of the electrospun nanofibers are given in Table 1. The mat thickness was increased with the increasing deposition time, as expected. The lowest average value achieved was nearly $4 \mu \mathrm{m}$ for the sample deposited for 1 minute, while the highest average value was almost $42 \mu \mathrm{m}$ for the sample deposited for 10 minutes.

Changing deposition time doesn't have any effect on fiber morphology. It only changes the number of the nanofibers deposited on the glass slide. Figure 3 shows the general surface topography of the produced nanofibers before and after the reduction process. Randomly aligned, smooth nanofibers with uniform diameters were produced. The diameters of the nanofibers were around $700 \mathrm{~nm}$. It was seen that the reduction process did not change or damage the nanofiber structure significantly.

Increasing the contact points between the nanofibers decreases the sheet resistance. With the increasing deposition time, the nanofiber amount and the number of contact points between the nanofibers increases leading to a decrease in the sheet resistance [38]. The sheet resistance values of the samples were changed in the range of 43.34 to $1.16 \mathrm{M} \Omega / \mathrm{sq}$ depending on the deposition time. The lowest sheet resistance was achieved for the sample deposited for 10 minutes (Table 1). Electrical conductivity is inversely correlated to sheet resistance. Therefore, a decrease in the sheet resistance indicates an increase in the electrical conductivity $[3,4,38]$.
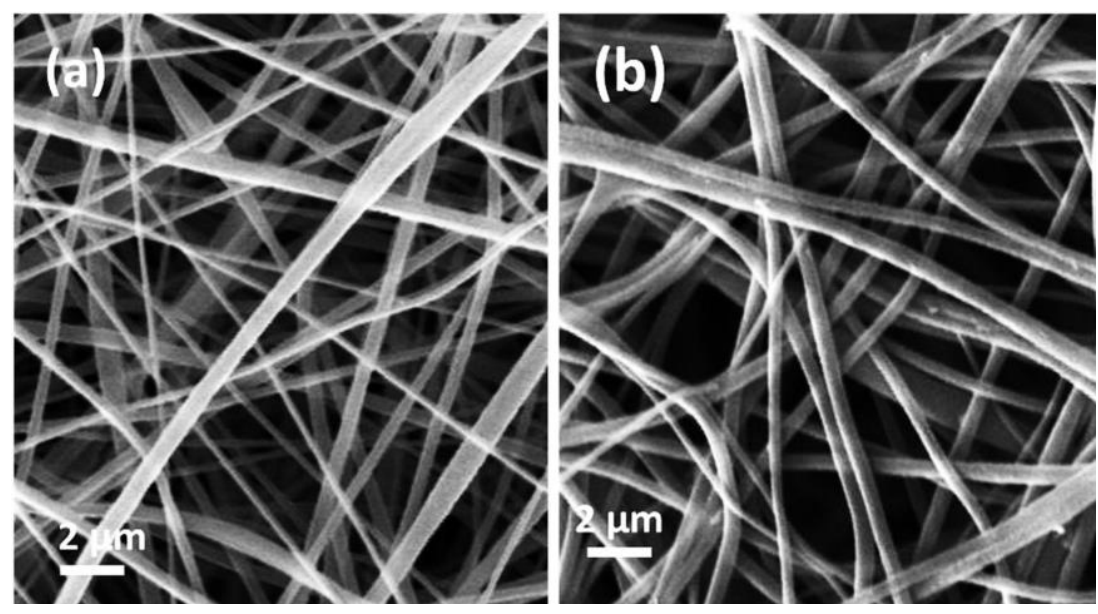

Figure 3. SEM image of the nanofibers a) before, b) after reduction with $\mathrm{NaBH}_{4}$

Table 1. Experimental results

\begin{tabular}{|c|c|c|c|c|}
\hline $\begin{array}{l}\text { Deposition Time } \\
\text { (min) }\end{array}$ & $\begin{array}{l}\text { Mat Thickness } \\
(\mu \mathrm{m})\end{array}$ & $\begin{array}{l}\text { Sheet Resistance (Rs) } \\
(\mathrm{M} \Omega / \mathrm{sq})\end{array}$ & $\begin{array}{c}\text { Transmittance }(\mathrm{T}) \\
(\%)\end{array}$ & $\begin{array}{l}\text { Figure of Merit }\left(\Phi_{\mathrm{TC}}\right) \\
(1 / \Omega)\end{array}$ \\
\hline 1 & $3.80 \pm 0.84$ & $43.34 \pm 2.42$ & $96.45 \pm 0.29$ & $156 \times 10^{-9} \pm 0.926 \times 10^{-9}$ \\
\hline 2 & $7.40 \pm 1.82$ & $26.49 \pm 8.07$ & $94.57 \pm 1.05$ & $216 \times 10^{-9} \pm 3.96 \times 10^{-9}$ \\
\hline 3 & $11.40 \pm 2.07$ & $14.79 \pm 2.90$ & $90.31 \pm 2.73$ & $242 \times 10^{-9} \pm 5.42 \times 10^{-9}$ \\
\hline 4 & $15.80 \pm 2.28$ & $9.78 \pm 1.65$ & $80.44 \pm 6.25$ & $126 \times 10^{-9} \pm 7.80 \times 10^{-9}$ \\
\hline 5 & $21.40 \pm 5.13$ & $6.38 \pm 2.34$ & $72.11 \pm 4.97$ & $5.51 \times 10^{-9} \pm 2.30 \times 10^{-9}$ \\
\hline 6 & $24.80 \pm 6.06$ & $5.07 \pm 1.49$ & $69.94 \pm 4.40$ & $4.64 \times 10^{-9} \pm 2.26 \times 10^{-9}$ \\
\hline 7 & $31.60 \pm 6.07$ & $3.26 \pm 1.62$ & $58.45 \pm 8.86$ & $1.83 \times 10^{-9} \pm 1.75 \times 10^{-9}$ \\
\hline 8 & $34.80 \pm 5.40$ & $2.82 \pm 1.38$ & $55.08 \pm 8.35$ & $1.27 \times 10^{-9} \pm 1.14 \times 10^{-9}$ \\
\hline 9 & $37.80 \pm 4.92$ & $2.18 \pm 1.48$ & $51.47 \pm 6.34$ & $0.663 \times 10^{-9} \pm 0.347 \times 10^{-9}$ \\
\hline 10 & $41.80 \pm 4.32$ & $1.16 \pm 0.98$ & $46.31 \pm 2.70$ & $0.416 \times 10^{-9} \pm 0.288 \times 10^{-9}$ \\
\hline
\end{tabular}


Transparency of the nanofibers is low. Therefore, an increase in the number of nanofibers in a defined area leads to a decrease in the transparency. Table 1 shows the change in optical transmittance values depending on the deposition time. The visible spectrum (380-750 nm spectrum band) was considered for each sample. Highest transmittance ( 96\%) was achieved for the samples deposited for $1 \mathrm{~min}$ and lowest transmittance $(\sim 46 \%)$ was achieved for the samples deposited for $10 \mathrm{~min}$.

Optical transparency and sheet resistance are crucial for optoelectrical applications. A good optoelectrical device should have both high optical transparency and low sheet resistance. In this study, increasing the number of nanofibers decreases the sheet resistance and the transparency, as expected. Therefore, a good balance between sheet resistance and transparency should be achieved. The figure of merit $\left(\Phi_{\mathrm{TC}}\right)$ can be used for this purpose [33-37]. In this study, the highest figure of merit was achieved for the samples deposited for 3 minutes indicating that they have better optoelectrical properties than the other samples (Figure 4, Table 1). This means that, 3-minute deposited nanofibers have the best performance within all the samples in terms of transparency and sheet resistance.

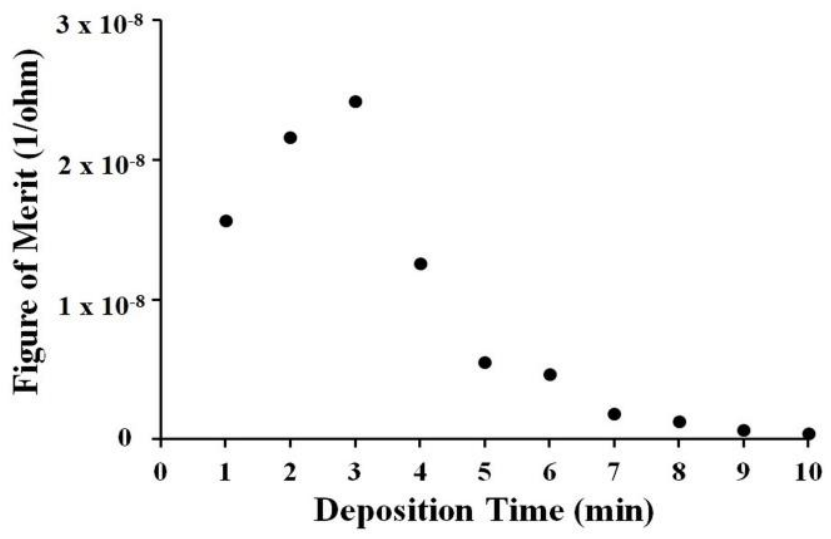

Figure 4. Figure of merit values of the samples

\section{CONCLUSIONS}

The significance of this study is to characterize the electrical and optical properties of the conductive $\mathrm{PAN} / \mathrm{AgNO}_{3}$ nanofibers. $\mathrm{PAN} / \mathrm{AgNO}_{3}$ nanofibers were produced by electrospinning with different deposition times ranging from 1 minute to 10 minutes and the effect of deposition time on the electrical and optical properties of PAN/AgNO nanofibers was investigated.

$\mathrm{PAN} / \mathrm{AgNO}_{3}$ nanofibers with smooth surfaces were successfully produced. In order to obtain Ag within the fiber, a reduction process was performed. The samples were characterized in terms of their surface morphology, optical transparency and electrical conductivity.

With the increasing deposition time, the sheet resistance and the optical transparency of the samples were decreased. The lowest sheet resistance $(1.16 \mathrm{M} \Omega / \mathrm{sq})$ was achieved for the sample deposited for 10 minutes. In addition, these samples gave the lowest optical transparency with a value of $46.31 \%$.

In order to compare the performances of the samples, the figures of merit were calculated. The nanofibers deposited for 3 minutes gave the highest figure of merit value. This indicates that sample deposited for 3 minutes have the best optoelectrical properties.

This study shows that, electrically conductive and optically transparent nanofibrous surfaces can be successfully produced by electrospinning with the addition of $\mathrm{AgNO}_{3}$ into the spinning solution. Although the sheet resistance values are relatively high, $\mathrm{PAN} / \mathrm{AgNO}_{3}$ nanofibers are promising for optoelectrical applications.

\section{ACKNOWLEDGEMENTS}

The author would like to thank Assoc. Prof. Dr. Serpil Koral Koc and Dr. Serkan Tezel for their fruitful contributions to the study. This study is financially supported by The Scientific and Technological Research Council of Turkey (TUBITAK) with the project number of $118 \mathrm{M} 670$.

\section{REFERENCES}

1. Hu L, Wu H, Cui Y. 2011. Metal nanogrids, nanowires, and nanofibers for transparent electrodes, MRS Bulletin Cambridge, 36(10), 760-776.

2. Wu H, Hu L, Rowell MW, Kong D, Cha JJ, McDonough JR, Zhu J, Yang Y, McGehee MD, Cui Y. 2010. Electrospun metal nanofiber webs as high-performance transparent electrode, Nano Lett. 10(10), 4242-4248.

3. Tezel S. 2018, November. Measurement of Electrical Conductivity Properties of Knitted Fabrics, International Euroasian Conference on Science, Engineering and Technology, Ankara, Turkey.

4. Ghorbani MM, Taherian R. 2019. Methods of measuring electrical properties of material. In Taherian, R. \& Kausar A. (Ed.), Electrical conductivity in polymer-based composites, experiments, modelling,

and applications. Oxford, United Kingdom: William Andrew Publishing, 365-394.

5. Ellmer K. 2012. Past achievements and future challenges in the development of optically transparent electrodes, Nature Photonics 6, 809-817.

6. Liu Z, Parvez K, Li R, Dong R, Feng X, Müllen K. 2015. Transparent Conductive Electrodes from Graphene/PEDOT:PSS hybrid inks ultrathin organic photodetectors, Adv. Mater. 27, 669-675.

7. Chen Z, Li W, Li R, Zhang Y, Xu G, Cheng H. 2013. Fabrication of highly transparent and conductive indium-tin oxide thin films with a high figure of merit via solution processing, Langmuir 29(45), 1383613842 . 
8. De S, Coleman JN. 2010. Are there fundamental limitations on the sheet resistance and transmittance on thin graphene films?, ACS Nano, 4(5), 2713-2720.

9. Guo H, Lin N, Chen Y, Wang Z, Xie Q, Zheng T, Gao N, Li S, Kang J, Cai D, Peng DL. 2013. Copper nanowires as fully transparent conductive electrodes, Scientific Reports 3:2323, 1-8.

10. Minami T. 2005. Transparent conducting oxide semiconductors for transparent electrodes, Semiconductor Science and Technology 20(4), $35-44$.

11. Huang ZM, Zhang YZ, Kotaki M, Ramakrishna S. 2003. A review on polymer nanofibers by electrospinning and their applications in nanocomposites. Comp. Sci. and Technol. 63 (15), 2223-2253.

12. Bhardwaj N, Kundu SC. 2010. Electrospinning: a fascinating fiber fabrication technique. Biotechnol. Adv. 28, 325-347.

13. Greiner A, Wendorff JH. 2007. Electrospinning: a fascinating method for the preparation of ultrathin fibers, Angew. Chemie Int. Ed. 46 , 5670-5703.

14. Li D, Xia Y. 2004. Electrospinning of Nanofibers: Reinventing the Wheel?, Adv. Mater. 16, 1151-1171.

15. Ko FK, El-Aufy A, Lam H, Macdiarmid AG. 2005. Electrostatistically generated nanofibers for wearable electronics. In Tao, X. (Ed.), Wearable electronics and photonics, Cambridge, England, Woodhead Publishing, 13-40.

16. Duzyer S. 2019. Different Methods of Fabricating Conductive Nanofibers, Tekstil ve Konfeksiyon 29(1), 78-85.

17. Li H, Pan W, Zhang W, Huang S, Wu H. 2013. TiN Nanofibers: A New Material with High Conductivity and Transmittance for Transparent Conductive Electrodes, Adv. Funct. Mater. 23(2), 209214.

18. MacDiarmid AG. 2001. "Synthetic Metals": A Novel Role for Organic Polymers (Nobel Lecture), Angew. Chemie Int. Ed. 40(14), 2581-2590.

19. Zhao W, Yalcin B, Cakmak M. 2015. Dynamic assembly of electrically conductive PEDOT: PSS nanofibers in electrospinning process studied by high speed video, Synth. Met. 203, 107-116.

20. Wang Y, Jing X. 2007. Transparent conductive thin films based on polyaniline nanofibers, Mater. Sci. Eng., B. 138, 95-100.

21. Chronakis IS, Grapenson S, Jakob A. 2006. Conductive polypyrrole nanofibers via electrospinning: Electrical and morphological properties, Polymer 47(5), 1597-1603.

22. Ko F, Gogotsi Y, Ali A, Naguib N, Ye H, Yang GL, Li C, Willis P. 2003. Electrospinning of continuous carbon nanotube-filled nanofiber yarns, Adv. Mater. 15(14), 1161-1165.

23. Fu Y, Liu L, Zhang L, Wang W. 2014) Highly conductive onedimensional nanofibers: silvered electrospun silica nanofibers via poly(dopamine) functionalization, ACS Appl Mater Interfaces. 6(7), 5105-5112.

24. Demirsoy N, Uçar N, Önen A, Karacan I, Kızıldağ I, Eren O, Borazan I. 2014. The effect dispersion technique, silver particle loading and reduction method on the properties of polyacrylonitrile-silver composite nanofiber, Journal of Industrial Textiles 45(6), 1173-1187.
25. Son WK, Youk JH, Park WH. 2006. Antimicrobial cellulose acetate nanofibers containing silver nanoparticles, Carbohydrate Polymers 65 , 430-434.

26. Lin SC, Ma CCM, Hsiao ST, Wang YS, Yang CY, Liao WH, Li SM, Wang JA, Cheng TY, Lin CW, Yang RB. 2016. Electromagnetic interference shielding performance of waterborne polyurethane composites filled with silver nanoparticles deposited on functionalized graphene, Applied Surface Science 385, 436-444.

27. Kim HR, Kim BS, Kim CS. 2012. Fabrication and EMI shielding effectiveness of Ag-decorated highly porous poly(vinyl alcohol)/ $/ \mathrm{Fe}_{2} \mathrm{O}_{3}$ nanofibrous composites, Material Chemistry and Physics 135, 10241029.

28. Ucar N, Demirsoy N, Onen A, Karacan I, Kizildag N, Eren O, Vurur OF, Sezer E, Ustamehmetoglu B. 2015. The effect of reduction methods and stabilizer (PVP) on the properties of polyacrylonitrile (PAN) composite nanofibers in the presence of nanosilver, Journal of Materials Science 50(4), 1855-1864.

29. Rashid MU, Bhuiyan Md. KH, Quayum ME. 2013. Synthesis of silver nano particles (Ag-nps) and their uses for quantitative analysis of vitamin c tablets, Dhaka Univ. J. Pharm. Sci. 12(1), 29-33.

30. Çunayev Ş, Düzyer Ş, Tezel S, Koral Koç S. 2019, April. Effect of reduction time on the electrical properties of $\mathrm{PAN} / \mathrm{AgNO}_{3}$ nanofibers, $2^{\text {nd }}$ International Congress on Engineering and Life Sciences (ICELIS), Kastamonu, Turkey.

31. Alam AM, Liu Y, Park M, Park SJ, Kim HY. 2015. Preparation and characterization of optically transparent and photoluminescent electrospun nanofiber composed of carbon quantum dots and polyacrylonitrile blend with polyacrylic acid, Polymer, 59, 35-41.

32. Banerjee AN, Maity R, Chattopadhyay KK. 2003. Preparation of ptype transparent conducting $\mathrm{CuAlO}_{2}$ thin films by reactive DC sputtering, Materials Letters 58, 10-13

33. Kim YS, Park JH, Choi DH, Jang HS, Lee JH, Park HJ, Choi JI, Ju DH, Lee JY, Kim D. 2007. ITO/Au/ITO multilayer thin films for transparent conducting electrode applications, Appl. Surf. Sci. 254, 1524-1527.

34. Fraser DB, Cook HD. 1972. Highly conductive transparent films of sputtered $\mathrm{In}_{2-\mathrm{x}} \mathrm{Sn}_{\mathrm{x}} \mathrm{O}_{3-\mathrm{y}}$, J.Electrochem. Soc.:Solid-State Science and Technology 119(10), 1368-1374.

35. Haacke G. 1976. New figure of merit for transparent conductors, $J$. Appl. Phys. 47, 4086-4089.

36. Knickerbocker SA, Kulkarni AK. 1995. Calculation of the figure of merit for indium tin oxide films based on basic theory, Journal of Vacuum Science \& Technology A 13, 1048-1052.

37. Song R, Li X, Gu F, Fei L, Ma Q, Chai Y. 2016. An ultra-long and low junction-resistance Ag transparent electrode by electrospun nanofibers, RSC Advances 6, 91641-91648.

38. Munir MM, Iskandar F, Yun KM, Okuyama K, Abdullah M. 2008. Optical and electrical properties of indium tin oxide nanofibers prepared by electrospinning, Nanotechnology 19, 145603:1-6. 